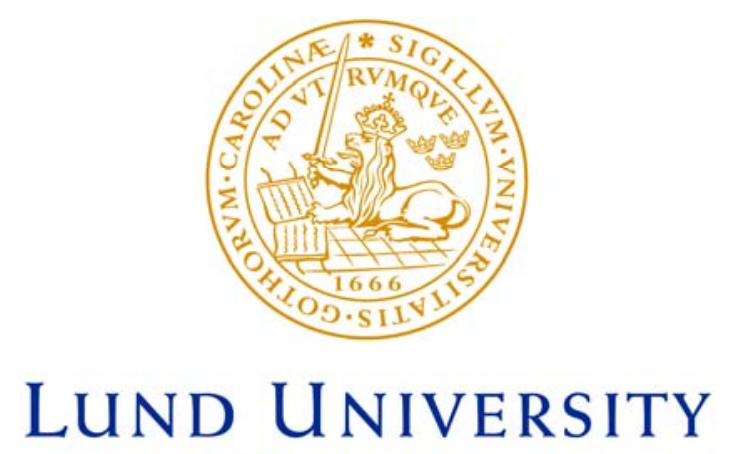

Faculty of Medicine

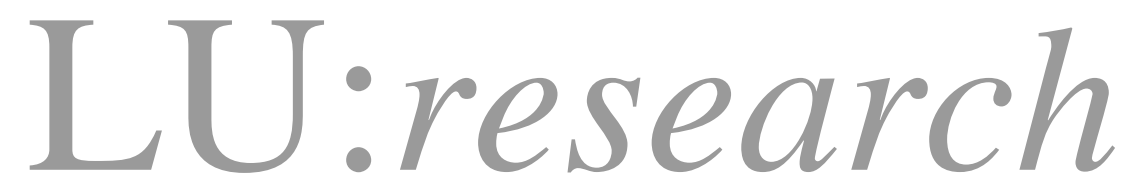

Institutional Repository of Lund University

This is an author produced version of a paper published in Occupational therapy international. This paper has been peer-reviewed but does not include the final publisher proof-corrections or journal pagination.

Citation for the published paper:

Werngren-Elgstrom, Monica and Brandt, Ase and Iwarsson, Susanne.

"Everyday activities and social contacts among older deaf sign language users: relationships to health and well-being"

Occupational therapy international, 2006, Vol: 13, Issue: 4, pp. 207-23.

Access to the published version may require journal subscription.

Published with permission from: John Wiley \& Sons 


\section{EVERYDAY ACTIVITIES AND SOCIAL CONTACTS \\ AMONG OLDER DEAF SIGN LANGUAGE USERS: \\ Relationships to health and wellbeing}

\section{Monica Werngren-Elgström, Åse Brandt, Susanne Iwarsson}

\section{Corresponding Author}

Monica Werngren-Elgström, LicMSc, Reg. OT

Department of Health Sciences, Division of Occupational Therapy, Faculty of Medicine, Lund University, Box 157, S-221 00 Lund, Sweden.

Tel: +46 4622219 50, Fax: +46 462221959

Email: Monica.Werngren-Elgstrom@med.lu.se

\section{Co-authors}

Åse Brandt, PhD, Reg. OT

Department of Research and Development, Danish Centre for Assistive Technology, P.P. Ørumsgade 11, Bygning 3, DK-8000 Århus C, Denmark.

Tel: +45 87412 407, Fax: +4586743667

Email:AAB@hmi.dk

Susanne Iwarsson, PhD, Reg. OT

Department of Health Sciences, Division of Gerontology and Caring Sciences, Faculty of Medicine,

Lund University, Box 157, S-221 00 Lund, Sweden.

Tel: +46 4622219 40, Fax: 46462221934

Email: Susanne.Iwarsson@med.lu.se

\section{Acknowledgement}

Thanks to V. Horstmann, LicSc, for statistical advice. This project was financially supported by The Swedish Council for Working Life and Social Research (FAS) and the Swedish Research Council. 


\section{ABSTRACT}

The purpose of this study was to describe the everyday activities and social contacts among older deaf sign language users, and to investigate relationships between these phenomena and the health and wellbeing within this group. The study population comprised deaf sign language users, 65 years or older, in Sweden. Data collection was based on interviews in sign language, including open-ended questions covering everyday activities and social contacts as well as self-rated instruments measuring aspects of health and subjective wellbeing. The results demonstrated that the group of participants was homogeneous in their productive and leisure activities, regardless of gender and age. The number of productive activities was related to all aspects of health, while the number of leisure activities was related to perceived health and subjective wellbeing. No significant relationship was found between aspects of health and subjective wellbeing and the frequency of social contacts with family/relatives or of visits at the deaf club meeting friends. It is concluded that the variety of activities at the deaf clubs are important for the subjective wellbeing of older deaf sign language users. Further research should investigate the importance and perceived value of the various activities at the deaf clubs. When evaluating the results of this study, the fact that the total number of participants was small, and the dropout rate was high, has to be borne in mind.

Keywords: deaf club, productive and leisure activities, deaf sign language users 


\section{INTRODUCTION}

Very few studies focus on older deaf people who use sign language as their main mode of communication and very little is known about their health and wellbeing, and their everyday life. This group, older deaf sign language users, consists of persons with congenital or early acquired hearing impairment, that prevents the natural development of spoken language (Heiling, 1993). However, Werngren-Elgström et al. (2003b) demonstrated in a previous study that a sample of older deaf persons (65 years or older) reported high levels of ill-health symptoms and depression, while at the same time perceiving their wellbeing as high. Severe hearing loss is a common disability, ranking third amongst chronic condition among older people (Heine \& Browning, 2002). For this group, it has been shown that hearing impairment is related to other comorbid conditions (Crews \& Campbell, 2004) and symptoms of depression (CapellaMcDonnall, 2005; Chou \& Chi, 2002; Strawbridge et al., 2000). It also adversely restricts several dimensions of quality of life (Jerger et al., 2003; Kramer et al., 2002) and negatively affects feelings of wellbeing (Heine \& Browning, 2002). Acquired hearing loss in old age is furthermore associated with limitations in daily activities and social participation (Crews \& Campbell, 2004; Kramer et al., 2002; Stephens et al., 2003). Stephen et al. (2003) thus reported that 69 per cent of their respondents indicated that community, social and civic life (mainly leisure activities) was negatively affected by their hearing loss.

The finding that older deaf sign language users report high levels of subjective wellbeing, while acquired hearing loss in old age is associated with decreased wellbeing, seems paradoxical. Could it be that a deepened knowledge of types and numbers of activity and frequencies of social contacts among older deaf sign language 
users could provide us with a clue for understanding the high levels of subjective wellbeing within this group?

Deaf people who use sign language are often excluded from gerontological studies (Andersson et al., 2000; Ringdahl \& Grimby, 2000). Furthermore, they are in general reluctant to contact healthcare personnel (Barnett \& Franks, 2002; Meador \& Zazove, 2005). There is therefore a lack of knowledge about older deaf sign language users health status, activity repertoires and social contacts and about the actual relationships between these variables. What we do know from the literature on deaf sign language users is that their participation in local deaf clubs provides opportunities to have contacts with friends and to engage in meaningful leisure activities (Lane et al., 1996). It has been claimed that deaf clubs constitute a central part of the social lives of deaf people (Backenroth, 1993; Fredäng, 2003).

It is widely accepted that an active life is positively associated with better health (Mendes de Leon et al., 2003; Wilcock, 1998). Engagement in meaningful activities has been identified as having a crucial importance in promoting and maintaining health and wellbeing throughout life (Christiansen, 1996; Law et al., 1998). Among older people, cognitive and social activities have been found to be associated with a decreased risk of dementia (Wang et al., 2002) and an active life in a broad sense has been shown to decrease the risk of becoming depressed (Avlund et al., 1999). Mendes de Leon et al. (2003) found that higher levels of leisure and productive activity among older adults were associated with reduced disability, while Menec (2003) demonstrated that meaningful and purposeful activities were related not only to greater wellbeing but also to reduced mortality over a 6-year span. 
There is reason to assume that repertoires of activity, that is, what persons prefer to do, are related to gender and age differences (Di Mauro et al., 2001; Smith \& Baltes, 1998). For example, older women are more involved in domestic activities, while older men prefer outside household tasks (Desrosiers et al., 2003) or are engaged in leisure activities (Klumb \& Baltes, 1999). Likewise, older men are more engaged in physical activities compared to older women of the same age (Fone \& Lundgren-Lindquist, 2003). As for age differences, it has been found that persons older than 75 years become more prone to engage in passive activities such as watching TV or reading (Desrosiers et al., 2003; Fone \& Lundgren-Lindquist, 2003).

Social contacts and networks are also essential to experiences of wellbeing and are keys to an active and satisfactory life in old age (Ståhl et al., 2001; Sørensen et al., 2002). Degree of satisfaction with social contacts is closely connected with feelings of isolation among older people (Holmén \& Furukawa., 2002), while an extensive social network can delay the onset of dementia (Fratiglioni et al., 2000). Frequent contacts with family and friends may thus counteract social loneliness (Drageset, 2004).

Against this background, an investigation into the activity repertoires and social contacts, and their relationship to aspects of health and subjective wellbeing, could shed further light on the finding that older deaf sign language users perceive their wellbeing as high despite high levels of ill-health. The purpose of this study was, first, to describe everyday activities and social contacts among older deaf sign language users and to study differences according to gender and age groups. A second purpose was to investigate relationships between everyday activities and social contacts on the one hand and aspects of health and wellbeing on the other. The hypothesis proposed is that a 
high number of activities and high frequency of social contacts, and in particular those related to deaf club activities, is positively related to health and wellbeing

\section{METHOD}

\section{Study design}

This descriptive study has an explorative and cross-sectional design and is based on interviews in sign language. The interviews were conducted in the respondents' own homes, except in two cases where the interviews were performed in the premises of a deaf club. The Ethics Committee at Lund University approved the study.

\section{Study population}

Data on the participants were obtained from multiple sources, such as interpretation and auditory rehabilitation services, deaf clubs and community care organisations, including nursing homes. As detailed in a previous article (Werngren-Elgström et al., 2003a), all older deaf sign language users, i.e. 65 years or older $(\mathrm{N}=109)$, registered as living in the county of Scania, Sweden, were informed about the study and invited to participate. Four of them died before data collection was finished. Eight persons, who suffered from blindness or known severe cognitive impairment that could interfere with interviews, were excluded. Thus, the study population comprised 97 persons.

Twenty persons (21\%) did not respond to the invitation to participate in the study. Another thirty-two persons (33\%) responded but did not want to participate. A postal questionnaire was distributed to both these groups $(n=52)$ in order to carry out a dropout analysis. Unfortunately, as the response rate despite a reminder was very low (29\%) the results of such an analysis would not have been valid, and thus the dropout data were 
not used. The final sample after dropouts consisted of 45 deaf persons that constituted $46 \%$ of the study population. The median age of the respondents was 75 years (ranging from 65 to 92). Gender and age groups characteristics are demonstrated in Table 1.

Data on how the studied group of older deaf sign language rated ill-health symptoms, depressive symptoms, perceived health and subjective wellbeing, more extensively reported in Werngren-Elgström et al. (2003b), are described in Table 1. No significant differences regarding gender or age groups were found in these respects.

Table 1 in here

\section{Instruments and data collection}

The interview schedule included a combination of self-rated instruments measuring different aspects of health and wellbeing and open-ended questions designed to investigate everyday activities and social contacts. The Gothenburg Quality of Life Instrument (GQL) (Tibblin et al., 1990) was used to measure subjective wellbeing, perceived health and ill-health symptoms. The GQL instrument comprises two parts, the first part covering subjective wellbeing including six physical, five mental, and seven social items. The respondent rates each item on a seven-step ordinal scale from "very bad" (=1) to "excellent, could not be better" (=7). Two items, viz. "work" and "hearing”, were considered irrelevant for the targeted group and were therefore not administrated. After data collection, another item, "sense of appreciation at home”, was excluded due to high internal dropout. Given the exclusion of these three items the maximum score was 105. The internal consistency (Cronbach, 1951) of the subjective wellbeing scale was alpha=0.87. An overall assessment of the respondents' perceived 
health was obtained by using the ratings of the single item "health" in the first part of GQL. Ill-health symptoms were measured by the second part of the GQL instrument, covering 30 different symptoms. Here, the respondents answered "yes" or "no" to questions about experiences of the symptoms during the last three months.

Furthermore, depressive symptoms were rated with the 15-item version of Geriatric Depression Scale (GDS) (Sheijk \& Yesavage, 1986). Since every item in this scale gives a score of 0 or 1 , the maximum score of the GDS scale is 15 . A score of $6-$ 10 is considered indicative of mild depression and a score of 11-15 signifies severe depression. The internal consistency (Cronbach 1951) of the GDS scale was alpha $=0.76$.

Most commonly and according to recommendations for administration, the GQL instrument should be self-administered. Given the specific circumstances of the present study, as there is a relatively high risk that deaf sign language users misunderstand nuances of written language, not least medical vocabulary (Göransson \& Malmström, 2002; Harmer, 1999), every interview question in the GQL, as well as the GDS, instruments and their response alternatives were signed. This was done to help the respondents to comprehend the written formulations and ensure validity and reliability.

In order to capture older deaf sign language users' own view of their everyday activities, signed open-ended questions were asked addressing what the respondents actually did during the day when they were not at the deaf club, and what activities they were engaged in when visiting the deaf club. The questions regarding social contacts addressed, (a) if and how often the respondents saw their children or relatives and, (b) if and how often they visited the deaf club to meet their friends. Whenever answers were 
brief and uninformative, follow-up questions were asked to prod the respondent to elaborate on his/her answer.

As sign language has no written form (Fredäng, 2003), each answer was written in Swedish by the interviewer. Interviewing deaf sign language users is time-consuming and requires a good understanding of sign language and deaf culture; each interview lasted between two and three hours.

\section{Data analysis and statistics}

All activities reported during the interviews were listed. Two experiences occupational therapists (first and second authors) as a first step discussed different alternatives of categorization, and decided to classify the activities reported according to two main categories, productive and leisure activities. Productive activities involve a person's strategies to maintain his/her social and/or economic community, including domestic activities, caring for family members, house and garden, and paid work (Turner et al., 2002). Leisure activities are undertaken for pleasure and contain a wide range of activities, partly culturally determined (Turner et al., 2002), including physical and social activities as well as more solitary cognitive activities such as watching television, reading and solving cross-word puzzles. In a next step, the first author independently classified the activities in the two main categories into sub-categories. The second author confirmed the proposed categorization. Productive activities were classified into the three sub-categories; “domestic activities”, “caring for family and house” and "work" whereas leisure activities were categorized into the four sub-categories; “physical activities”, “cognitive activities”, “social activities outside the deaf club” and “social activities outside the deaf club” (see Table 2). 
Each respondent was registered as reporting "performing” or "not performing” each listed activity. For each listed activity, the total number of respondents reporting that they performed it was computed. Differences in performing the various activities according to gender and age group were calculated. To make it possible to compute relationships between categories/sub-categories of activities and different aspects of health and wellbeing, (a) the number of activities in each sub-category, (b) the total number of productive activities and leisure activities, and (c) the total number of all activities reported by each respondent were calculated.

"Social contacts" is in this study used in a precise, quantitative and rather limited sense. The concept refers to structural and quantitative aspects of relationships (Drageset 2004). Structure is linked to whom you have contacts with and where, quantity refers to frequency, i.e. how often you have contacts. A difference was made between seeing family/relatives and seeing friends at the deaf club. Regarding frequencies of social contacts the responses were categorized into "often” (once a week or more), "sometimes” (1-3 times a month), or "seldom" (less than once a month). These categories were used when computing relationships between frequency of social contact and aspects of health and wellbeing. Due to small sample sizes when computing differences in frequencies of social contacts within gender and age groups, instead the categorization was dichotomized into "once a week or more" and "less than once a week".

When computing relationships, summed scores were used for ill-health symptoms, depressive symptoms and subjective wellbeing, while single ratings were used for perceived health. Relationships were computed by means of Spearman's rho, 
corrected for ties. In the various comparisons the Chi-squared test or Fisher's exact test were utilized. P-values $<0.05$ were considered statistically significant.

\section{RESULT}

\section{Productive and leisure activities and social contacts}

The analysis demonstrated that the vast majority of the studied group (approx. 80\%) reported performing domestic productive activities such as "preparing food”, "buying food" and "cleaning” (see Table 2). Regarding leisure activities, almost $60 \%$ of the respondents reported cognitive activities such as "watching television” and "reading”, and more than $40 \%$ reported some kind of hobby. The most frequent physical activity was “walking”. With respect to social activities outside the deaf club, a large proportion of the studied group (84\%) reported seeing their family/relatives and $60 \%$ saw their friends/neighbours. Concerning social activities within the deaf club, almost all (89\%) stated that they socialized at the deaf club, while just below half of the respondents (44\%) attended lectures or group excursions.

Table 2 in here

As demonstrated in Table 2, only few significant gender and age group differences regarding productive and leisure activities were found, and several of these differences concerned types of activities engaging very few respondents, such as "baking" ( $p=0.032)$, "house maintenance” ( $p=0.026)$ and “exercising” ( $p=0.049)$. More people in the younger age group, however, reported "buying food" ( $p=0.022)$, while more people 
in the older age group engaged in "watching television" ( $p=0.036)$ and "reading" $(p=0.016)$.

Concerning the frequencies of social contacts, almost half $(n=22)$ of the sample reported seeing their family/relatives once a week or more, while 16 persons (35\%) reported seeing them one to three times a month, and seven (15\%) stated that they met their family members less than once a month. More than half of the respondents $(n=25)$ visited the deaf club meeting friends once a week or more, eleven (24\%) were there one to three times a month, and nine persons (20\%) reported visiting the deaf club less than once a month. To summarize, around $80 \%$ of the studied group stated that they saw their family at least once a month, and a similar share of the respondents reported visiting the deaf club with the same frequency. Significantly fewer respondents $(p<0.05)$ in the older age group visited the deaf club than in the younger age group. No gender differences were found in this respect.

\section{Relationships between activity, social contacts and aspects of health and wellbeing}

Significant relationships were found between the total number of productive activities and ill-health symptoms, depressive symptoms and perceived health (see Table 3). The more productive activities reported, the lower the numbers of ill-health symptoms $\left(\boldsymbol{r}_{\mathrm{s}}=-\right.$ $0.42)$ and depressive symptoms $\left(r_{s}=-0.40\right)$ and the higher the perceived health $\left(r_{s}=0.37\right)$. When focusing on sub-categories of productive activities, "caring for family and house” was negatively related to ill-health symptoms $\left(r_{s}=-0.37\right)$ and depressive symptoms $\left(r_{s}=-\right.$ 0.31). The total number of leisure activities was positively related to both perceived health $\left(r_{s}=0.30\right)$ and subjective wellbeing $\left(r_{s}=0.38\right)$. In examining sub-categories of leisure activities, the only significant relationship was between social activities within 
the deaf club and subjective wellbeing $\left(\boldsymbol{r}_{\mathrm{s}}=0.34\right)$. The higher the number of social activities at the deaf club, the higher the wellbeing.

Table 3 in here

As shown in Table 3, the total sum of all reported activities performed was related to all health aspects and subjective wellbeing; positively related to perceived health $\left(r_{s}=0.46\right)$ and subjective wellbeing $\left(\boldsymbol{r}_{\mathrm{s}}=0.47\right)$ and negatively related to ill-health $\left(\boldsymbol{r}_{\mathrm{s}}=-0.34\right)$ and depressive symptoms $\left(\boldsymbol{r}_{\mathbf{s}}=-0.37\right)$. No significant relationships were found between the frequencies of social contacts and the health aspects and subjective wellbeing. This held true both for contacts with family/relatives and for deaf club visits meeting friends.

\section{DISCUSSION}

As regards the repertoire of activity among the older deaf sign language users studied, one finding is the role leisure activities within the deaf club play in their lives. This result is consistent with observations in previous research showing that deaf sign language users tend to interact internally and to concentrate their activities to deaf environments (Backenroth, 1993). Deaf clubs are claimed to "constitute a breathingspace, an arena for relaxed social interaction together with other people in the same situation” (Fredäng, 2003, p. 144) and provide a natural meeting place for this group of people, who often define themselves as a linguistic and cultural minority (Padden \& Humphries, 1988). Our results indicate the importance also for older deaf sign language users of being able to relate to a deaf community and of being able to carry out activities in a sign language speaking environment. It might be argued that social activities in 
such an environment, which forms a closely-knit community, constitute a specific form of compensation that replaces leisure activities in the "hearing society". Whether this is the case is a question for future research.

The focus of older deaf sign language users on activities at the deaf club, regardless of gender and age, constitutes a part of another finding: that the participants of older deaf sign language users is generally homogeneous in their repertoire of productive and leisure activities. That is, few significant gender and age group differences were found with regard to the types of activities reported. This can be contrasted to results from studies on older hearing people showing that older age groups (75 years and older) were less engaged in everyday activities compared to younger age groups (65-74 years) (Desrosiers, 2003; Klumb \& Baltes, 1999). The fact that almost no gender differences in reported activities were found stands in contrast with patterns among older hearing people, where considerable heterogeneity depending on gender exists (Di Mauro et al., 2001; Fone \& Lindgren-Lindquist, 2003; Klumb \& Baltes, 1999). However, our results on gender homogeneity need further corroboration. It might, for example, be that the studied group of male deaf sign language users, although reporting domestic activities, only play a secondary role in these activities and may still be dependent on their spouses in activities such as preparing food or cleaning (cf. Smith \& Baltes, 1998).

The few, mainly age-related, differences that were discovered in our study might be explained by the respondents having other functional limitations or dependence on mobility devices besides deafness that may restrict their repertoire of activities. Studies on older people have demonstrated a relationship between functional limitations and/or dependence on mobility devices, and dependence in daily activities (Dahlin-Ivanoff \& 
Sonn, 2004; Iwarsson, 2005). As deaf sign language users grow old, age-related functional decline such as visual impairment (cf. Reisser et al., 2002; Sslyk et al., 1997) and vestibular dysfunction (Möller et al., 1997) may restrict their repertoire of activities. Functional limitations that lead to dependence on mobility devices may, for example, make shopping more difficult or hinder the ability to get to and from deaf clubs (cf. Göransson \& Malmström, 2002). More research is however needed on which functional limitations exist among older deaf sign language users and on their effects on everyday activities, not least dependence in daily activities.

As regards social contacts, the respondents report frequent contacts with family/ relatives and frequent visits at the deaf club meeting friends. This finding indicates, following the suggestion by Drageset (2004) that frequent contacts with friends are related to low levels of social loneliness, that the studied group of older deaf sign language users does not experience social isolation, at least not in relation to their family or to the deaf community. Our results do not address, however, the frequently voiced concern that older deaf sign language users risk social exclusion from the hearing world (Harries \& Bamford, 2001), leading to loneliness and social isolation, especially if they are in need of long-term care facilities and are obliged to live in an otherwise hearing environment (Green \& Mosher-Ashley, 1997; Hutlock, 2004).

Turning to the relationship between activity and aspects of health and wellbeing, one finding of this study was that leisure activities seemed to be less related to ill-health than productive activities. This may be because productive activities are more physically demanding than many leisure activities, but also because the pleasure derived from leisure activities makes people continue with them despite ill-health (cf. Desrosiers et al., 2004; Menec \& Chipperfield, 1997). The fact that the total number of activities, 
both productive and leisure, was positively related to perceived health as well as to subjective wellbeing is consistent with previous gerontological research, which indicates that engagement in these kinds of activities has positive effects on perceived health and life satisfaction and are strongly associated with survival (Glass et al., 1999; Lennartsson \& Silverstein, 2001).

It is also worth emphasizing that social activities among our sample of older deaf sign language users, especially those taking place within the deaf clubs, are positively related to subjective wellbeing, suggesting - in line with existing research on older hearing people (Menec, 2003) - that such activities are associated with the successful ageing of older deaf sign language users. It should be noted, however, that a high level of subjective wellbeing might well result in high levels of activity (cf. Lennartsson \& Silverstein, 2001), that is, that the causal mechanism may also work in the opposite direction. Given the limited sample size of the current study, data analyses investigating causal relations would not have been valid, and thus our results do not shed any further light on these issues.

One possible interpretation of our results is that it is the variation, as indicated by the total number of different activities performed, and not the engagement in single subcategories of activity that is related to positive perceptions of health and wellbeing (cf. Mendes de Leon et al., 2003). No significant relationships were found, for example, between numbers of domestic, cognitive or physical activities and aspects of health and wellbeing. Instead, significant relationships were - consistent with our hypothesis found between the total number of activities and all aspects of health and subjective wellbeing. This suggests that a varied pattern of activities - including both productive and leisure activities - may be linked to health and wellbeing (Glass et al., 1999). 
The fact that no significant relationships were found between the frequency of visits at the deaf club and aspects of health and wellbeing can be interpreted as indicating that it is not how often you visit the deaf club but rather what you actually do there, that matters. The nature and importance of different deaf club activities for older deaf sign language users has, however, not been scrutinized in this study and should be subject to further research.

When evaluating the results of this study, some methodological issues have to be considered. The total number of older deaf sign language users was small, and the dropout rate was high. Unfortunately, according to Magilvy (1984), this is not unusual in studies of deaf people. Under such circumstances no generalizations of the results can be made. Still, the study is unique, due to the fact that the entire population was defined and targeted and that the interviews were carried out in sign language in the home environments of the respondents, which increases the validity of the data.

Our study is based on the perceptions of the respondents, i.e. on subjective aspects of activity, social contacts, health and wellbeing. As regards activity, other methods of data collection, such as video documentation, observations or diaries (Erlandsson \& Eklund, 2001) would have been possible. For our purposes, video and observation were impractical. The use of diaries could arguably have provided a more penetrating picture of everyday activities. However, such a method would presumably have produced an even higher dropout rate because of its time-consuming nature and the linguistic barrier it would have presented the group at target. In short there are few options in measuring variables with a deaf population that uses sign language.

In order to be able to calculate relations between activities and aspects of health and wellbeing, we added the number of different types of activities that the respondents 
reported that they usually carried out during the day. In doing so, all types of activities were treated as being of equal value. This means that we did not measure aspects such as the intensity and degree of importance or perceived value of activities (Eklund et al., 2003), which would potentially have provided information on how meaningful various activities were for the group at target. Certain types of activities may be more important than others, in the sense that they are of more central concern for the individuals involved. Further research is needed on investigating the activity choices of deaf individuals who rely on sign language. Similarly, the quality of social contacts was not recorded. Our finding that frequencies of social contacts are not significantly related to health and wellbeing might therefore be misleading; other studies indicate that it is indeed the quality of social contacts that is crucial in supporting health and wellbeing (Pinquart \& Sörensen, 2000). Furthermore, social connections are often cultivated in the context of leisure activities. Thus, it is not always "possible for investigators to distinguish whether benefits derive from the social aspects or from the actual content of the activities” (Lennartsson \& Silverstein 2001, p. S336).

\section{CONCLUSION}

The results of this study support the suggestion found in gerontological research in general that an active life style is related to better health and higher levels of subjective wellbeing. Some of our hypotheses were supported. That is, higher numbers of activities were positively related to health and subjective wellbeing, and the number of activities within the deaf club was positively related to subjective wellbeing. We conclude that activities within the deaf club seem to be beneficial for the subjective wellbeing of older deaf sign language users. It does not, however, seem to be the frequency of visits at the 
club, but rather the variety of activities carried out there, that matters. On the other hand, we found no significant relation between the number of activities within the deaf club and health, and there was no such relation between the frequency of social contacts and health and wellbeing.

\section{REFERENCES}

Anderson R, Ory M, Cohen S (2000). Issues of aging and adherence to health interventions. Controlled Clinical Trials, 21(5 suppl): 171-83.

Avlund K, Holstein B, Mortensen E, Schroll M (1999). Active life in old age. Danish Medcine Bulletin, 46: 345-49.

Backenroth G (1993). Loneliness in the deaf community: a personal or an enforced choice? International Journal of Rehabilitation Research, 16: 331-69.

Barnett S, Franks P (2002). Health care utilization and adults who are deaf: relationship with age at onset of deafness. Health Service Research, 37: 105-20.

Capella-McDonnall, M (2005). The effects of single and dual sensory loss on symptoms of depression in the elderly. International Journal of Geriatric Psychiatry, 20: 85561.

Chou K-L, Chi I (2002). Combined effects of vision and hearing impairment on depression on elderly Chinese. International Journal of Geriatric Psychiatry, 19: 825-32.

Christiansen C (1996). Three Perspectives on Balance in Occupation. In Zemke R, Clark F (eds) Occupational Science. The Evolving Discipline. Philadelphia: FA Davies Company, 
Crews J, Campbell V (2004). Vision impairment and hearing loss among communitydwelling older Americans: implications for health and functioning. American Journal of Public Health, 94: 823-29.

Cronbach LJ (1951). Coefficient alpha and the internal structure of tests. Psychometrika, 16: 296-334.

Dahlin-Ivanoff S, Sonn U (2004). Use of assistive devices in daily activities among 85years-olds living at home focusing especially on the visually impaired. Disability and Rehabilitation, 26(24): 1423-30.

Desrosiers J, Noreau L, Rochette A (2003). Social participation of older adults in Quebec. Aging and Clinical Experimental Research, 16: 406-12.

Di Mauro S, Scalia G, Di Maurio A, Di Fazio I, Giuffrida F, Leotta C, Grasso MG, Distefano A (2001). The leisure time and the third age: the experience of a geriatric day hospital. Archives of Gerontology and Geriatrics, 33: 141-50.

Drageset J (2004). The importance of activities of daily living and social contacts for loneliness: a survey among residents in nursing homes. Scandinavian Journal of Caring Sciences, 18: 65-71.

Eklund M, Erlandsson L-K, Persson D (2003). Occupational value among individuals with long-term intellectual illness. Canadian Journal of Occupational Therapy, 70: 276-84.

Erlandsson L-K, Eklund M (2001). Describing patterns of daily occupations - a methodological study comparing data from four different methods. Scandinavian Journal of Occupational Therapy, 8: 31-39. 
Fone S, Lundgren-Lindquist B (2003). Health status and functional capacity in a group of successful ageing 65 - 85 years olds. Disability and Rehabilitation, 25(18): $1044-51$.

Fratiglioni L, Wang H-X, Ericsson K, Maytan M, Winblad B (2000). Influence of social network on occurrence of dementia: a community-based longitudinal study. Lancet 335: 1315-19.

Fredäng P (2003). Teckenspråkiga döva. Identitetsförändringar i det svenska dövsamhället [Deaf Sign Language Users. Changes in identities in the Swedish deaf community, in Swedish]. Doctoral dissertation. Uppsala, Sweden: Department of Sociology, Uppsala University.

Glass T, Mendes de Leon C, Marottoli R, Berkman L (1999). Population based study of social and productive activities as predictor of survival among elderly Americans. BMJ, 319: 478-83.

Green A, Mosher-Ashley P (1997). A residential care alternative for elderly deaf persons. Journal of Gerontological Nursing, 23: 32-36.

Göransson L, Malmström S-E (2002). Döva i Skåne. Från projekt till regionalt resursteam för döva [Deaf in the County of Scania. From project to regional resource team, in Swedish]. Lund, Sweden: Region Skåne, FoU-enheten, Habilitering \& Hjälpmedel.

Harmer L (1999). Health care delivery and deaf people: practice, problems, and recommendations for change. Journal of Deaf Studies and Deaf Education, 4: 73110. 
Harries J, Bamford C (2001). The uphill struggle: services for Deaf and hard of hearing people - issues of equality, participation and access. Disability and Society 16: 969-79.

Heine C, Browning C (2002). Communication and psychosocial consequences of sensory loss in older adults: overview and rehabilitation directions. Disability and Rehabilitation, 24(15): 763-73.

Heiling K. (1993). Döva barns utveckling i ett tidsperspektiv. Kunskapsnivå och sociala processer [Deaf children's development in a temporal perspective. Academic achievement levels and social processes, in Swedish]. Doctoral dissertation. Stockholm: Almqvist \& Wiksell International.

Holmén K, Furukawa H (2002). Loneliness, health and social network among elderly people - a follow-up study. Archives of Gerontology and Geriatrics, 35, 261-74.

Hutlock T (2004). Breaking the silence. Nursing Homes, 53: 59-60.

Iwarsson S (2005). A long-term perspective on person-environment fit and ADL dependence among oleder Swedish adults. The Gerontologist, 45(3): 327-36.

Jerger J, Chmiel R, Wilson N, Luchi R (2003). Hearing impairment in older adults: New concepts. Journal of American Geriatrics Society, 43: 928-35.

Klumb P, Baltes M (1999). Time use of old and very old Berliners: productive and consumptive activities as functions of resources Journal of Gerontology: SOCIAL SCIENCES, 54B(5): S271-78.

Kramer S, Kapteyn T, Kuik D, Deeg D (2002). The Association of hearing impairment and chronic diseases with psychosocial health status in old age. Journal of Aging and Health, 14(1): 122-37. 
Lane H, Hoffmeister R, Bahan B (1996). A Journey into the Deaf-World. San Diego: DawnSignPress.

Law M, Steinwender S, Leclair L (1998). Occupation, health and well-being. Canadian Journal of Occupational Therapy, 65: 81-91.

Lennartsson C, Silverstein M (2001). Does engagement with life enhance survival of elderly people in Sweden? The role of social and leisure activities. Journal of Gerontology: SOCIAL SCIENCES,, 56B(6): S335-42.

Magilvy J (1984). Quality of life of hearing-impaired older women. Nursing Research, 34: $140-44$.

Meador H, Zazove P (2005). Health care interactions with deaf culture. Journal of American Board of Family Practice, 18(3): 218-22.

Mendes de Leon C, Glass T, Berkman L (2003). Social engagement and disability in a community population of older adults. American Journal of Epidemiology 157: 633-42.

Menec V (2003). The relation between everyday activities and successful aging: a 6year longitudinal study. Journal of Gerontology: SOCIAL SCIENCES, 58B(2): S74-82.

Menec V, Chipperfield J (1997). Remaining active in later life. The role of locus of control in seniors' leisure activity participation, health, and life satisfaction. Journal of Aging and Health, 9: 105-25.

Möller C, Berg K, Swartling L, Noaksson L (1997). Glöm inte andra halvan av organet! Viktigt att undersöka balans hos döva och hörselskadade. [Do not forget the other half of the organ! Important to examine balance in deaf and hearing impaired persons, in Swedish]. Läkartidningen, 94: 4479-80. 
Padden C, Humphries T (1988). Deaf in America: Voices from a culture. Cambridge: Harvard University Press.

Pinquart M, Sörensen S (2000). Influences of socioeconomic status, social network, and competence on subjective well-being in later life: a meta-analysis. Psychology and Aging, 15: 187-224.

Reisser C, Kimberling W, Otterstedde C (2002). Hearing loss in Usher syndrome type II is nonprogressive. Annals of Otology, Rhinology, and Laryngology, 111: 1108-11.

Ringdahl A, Grimby A (2000). Severe-profound hearing impairment and health-related quality of life among post-lingual deafened Swedish adults. Scandinavian Audiology, 29: 266-75.

Sheijk JL, Yesavage JA (1986). Geriatric depression scale (GDS): Recent evidence and development of a shorter version. In: Brink TL (ed.) Clinical Gerontology: A guide to assessment and intervention. Binghampton: Haworth Press.

Smith J, Baltes M (1998). The role of gender in very old age: Profiles of functioning and everyday life patterns. Psychology and Aging, 13(4): 676-95.

Sslyk J, Fishman G, Alexander K, Revelins B, Derlacki D, Anderson R (1997). Relationship between difficulty in performing daily activities and clinical measures of visual function in patients with retinitis pigmentosa. Archives of Ophthalmology, 115: 53-59.

Ståhl T, Rutten A, Nutbeam D, Bauman A, Kannas L, Abel T, Luschen G, Rodriquez DJ, Vinck J, van der Zee J (2001). The importance of the social environment for physically active lifestyle - results from an international study. Social Science \& Medicine, 52: 1-10. 
Stephens D, Vetter N, Lewis P (2003). Investigating factors effecting hearing aid candidature in the elderly. International Journal of Audiology, 42: 2S33-38.

Strawbridge W, Wallhagen M, Shema S, Kaplan G (2000). Negative consequences of hearing impairment in old age: A longitudinal analysis. The Gerontologist, 40(3): 320-26.

Sørensen LV, Axelsen U, Avlund K (2002). Social participation and functional ability from age 75 to age 80. Scandinavian Journal of Occupational Therapy, 9: 71-8.

Tibblin G, Tibblin B, Peciva S, Kullman S, Svärdsudd K (1990). “The Göteborg Quality of Life Instrument” - An assessment of wellbeing and symptoms among men born 1913 and 1923. Scandinavian Journal of Primary Health Care, Suppl, 1: 33-8.

Turner A, Foster M, Johnson S (2002). Occupational Therapy and Physical Dysfunction. Principles, skills and practice (5th edn). Edinburgh: Churchill Livingstone.

Wang H-X, Karp A, Winblad B, Fratiglioni L (2002). Late-life engagement in social and leisure activities is associated with a decreased risk of dementia: A longitudinal study from the Kungsholmen project. American Journal of Epidemiology, 155: 1081-87.

Werngren-Elgström M, Dehlin O, Iwarsson S (2003a). A Swedish prevalence study of deaf using sign language. A prerequisite for Deaf studies. Disability and Society, 18: 311-23.

Werngren-Elgström M, Dehlin O, Iwarsson S (2003b). Aspects of quality of life in persons with pre-lingual deafness using sign language: subjective wellbeing, ill- 
health symptoms depression and insomnia. Archives of Gerontology and Geriatrics, 37: $13-24$.

Wilcock A (1998). An Occupational Perspective on Health. Thorofare: Slack Incorporated. 
TABLE 1: Characteristics of the studied group of older deaf sign language users $(\mathrm{N}=45)$ according to age groups, gender and living situation, and different aspects of health and wellbeing.

\begin{tabular}{|c|c|c|c|}
\hline Characteristic & $\mathbf{n}$ & median & range \\
\hline \multicolumn{4}{|l|}{ Age group } \\
\hline $65-74$ years & 22 & & \\
\hline 75 years or older & 23 & & \\
\hline \multicolumn{4}{|l|}{ Gender } \\
\hline male & 19 & & \\
\hline female & 26 & & \\
\hline \multicolumn{4}{|l|}{ Aspects of health and wellbeing } \\
\hline Ill-health symptoms $(0-30)^{1}$ & & 8 & $0-20$ \\
\hline Depressive symptoms $(0-15)^{2}$ & & 3 & $0-11$ \\
\hline Perceived health (1-7) ${ }^{1}$ & & 5 & $4-7$ \\
\hline Subjective wellbeing (15-105) ${ }^{1}$ & & 87 & 57-101 \\
\hline
\end{tabular}

${ }^{1}$ Perceived health, ill-health symptoms and subjective wellbeing measured by the Gothenburg Quality of Life instrument (GQL) (Tibblin et al., 1990), as demonstrated in Werngren-Elgström et al. (2003b).

${ }^{2}$ Depressive symptoms measured by the Geriatric Depression Scale (GDS)

(Sheijk \& Yesavage, 1986), as demonstrated in Werngren-Elgström et al. (2003b). 
TABLE 2: Distribution of different types of productive and leisure activities reported by the studied group of older deaf sign language users and differences according to gender and age group ( $N=45)$.

\begin{tabular}{lccccccc}
\hline & Total & Female & Male & Diff. & $\begin{array}{c}65-74 \\
75 \text { years } \\
\text { years } \\
\text { or older } \\
n=26\end{array}$ & $\begin{array}{c}\text { Diff. } \\
(\%)\end{array}$ & $p$-value \\
\hline
\end{tabular}

\section{PRODUCTIVE ACTIVITY}

\section{Domestic activities}

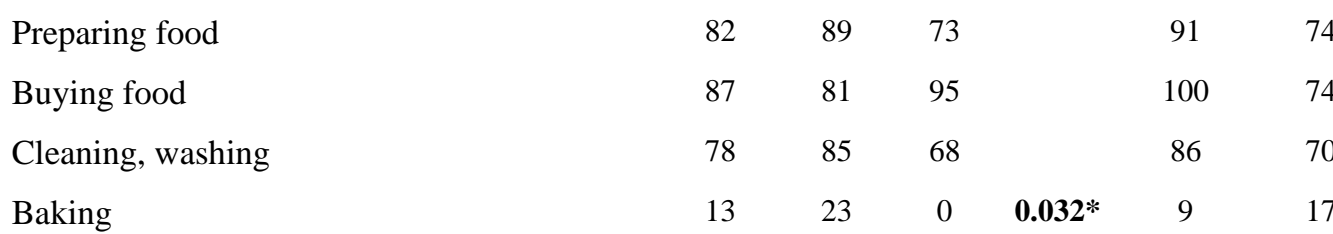

\section{Caring for family and house}

Caring for family members incl. pets

Gardening

House maintenance

\begin{tabular}{|c|c|c|c|c|}
\hline 16 & 15 & 16 & & 23 \\
\hline 18 & 8 & 32 & & 27 \\
\hline 10 & 0 & 21 & 0.026* & 14 \\
\hline
\end{tabular}

\section{Work}

Temporary work

$\begin{array}{lll}4 & 4 & 5\end{array}$

$9 \quad 0$

\section{LEISURE ACTIVITIES}

\section{Cognitive activities}

Watching TV

Reading

Writing, solving crosswords

Craft, needlework, collecting hobbies

\section{Physical activities}

Walking

Cycling

Exercising (e.g. gymnastics, badminton)

Social activities outside the deaf club

Seeing family/relatives

Seeing friends/neighbours

Visiting museums, exhibitions, café etc

\section{Social activities within the deaf club}

Socializing (e.g. talking and drinking coffee)

Playing card, bingo or quiz

Attending lectures or group excursions

Board meetings

Other activities (e.g. fishing, shooting)

$\begin{array}{lll}58 & 54 & 63 \\ 60 & 54 & 68 \\ 16 & 23 & 53 \\ 42 & 50 & 32\end{array}$

$\begin{array}{ll}50 & 74 \\ 41 & 78 \\ 9 & 22 \\ 46 & 39\end{array}$

0.036*

0.016*

$\begin{array}{lllll}44 & 42 & 47 & 59 & 30 \\ 13 & 8 & 21 & 18 & 9 \\ 9 & 4 & 16 & 18 & 0\end{array}$

0.049*

$\begin{array}{lllll}84 & 89 & 79 & 86 & 83 \\ 60 & 58 & 63 & 73 & 48 \\ 20 & 19 & 21 & 23 & 17\end{array}$

$\begin{array}{lllll}29 & 31 & 26 & 41 & 17\end{array}$

$\begin{array}{lllll}44 & 46 & 42 & 50 & 39\end{array}$

$\begin{array}{lllll}16 & 12 & 21 & 32 & 0\end{array}$

$0.004 * *$

$\begin{array}{lllllll}9 & 0 & 21 & \mathbf{0 . 0 2 6}^{*} & 18 & 0 & \mathbf{0 . 0 4 9 *}\end{array}$

Note: $*=p<0.05, * *=p<0.01$ 
TABLE 3. Relationships between activities and social contacts on the one hand, and aspects of health and wellbeing on the other.

\begin{tabular}{|c|c|c|c|c|}
\hline $\begin{array}{l}\text { Categories of activities and } \\
\text { frequency of social contacts }\end{array}$ & $\begin{array}{c}\text { Ill-health } \\
\text { symptoms }{ }^{1} \\
(\mathrm{~N}=45) r_{s}\end{array}$ & $\begin{array}{c}\text { Depressive } \\
\text { symptoms }{ }^{2} \\
(\mathrm{~N}=45) r_{s}\end{array}$ & $\begin{array}{c}\text { Perceived } \\
\text { health }{ }^{1} \\
(\mathrm{~N}=44) r_{s}\end{array}$ & $\begin{array}{c}\text { Subjective } \\
\text { wellbeing }{ }^{1} \\
(\mathrm{~N}=44) r_{s}\end{array}$ \\
\hline \multicolumn{5}{|l|}{ PRODUCTIVE } \\
\hline Domestic activities & -0.14 & -0.18 & 0.22 & 0.15 \\
\hline Caring for family and house & $-0.37 *$ & $-0.31 *$ & 0.29 & 0.21 \\
\hline Total number of productive activities & $-0.42^{* *}$ & $-0.40 * *$ & $0.37 *$ & 0.27 \\
\hline \multicolumn{5}{|l|}{ LEISURE } \\
\hline Cognitive activities & 0.14 & 0.13 & 0.02 & 0.08 \\
\hline Physical activities & -0.03 & -0.11 & 0.14 & 0.05 \\
\hline Social activities outside the deaf club & -0.17 & -0.11 & 0.03 & 0.16 \\
\hline Social activities within the deaf club & -0.17 & -0.28 & 0.17 & $0.34 *$ \\
\hline Total number of leisure activities & 0.12 & -0.23 & $0.30^{*}$ & $0.38 *$ \\
\hline TOTAL NUMBER OF ACTIVITIES & $-0.34^{*}$ & $-0.37 *$ & $0.46^{* *}$ & $0.47^{* *}$ \\
\hline \multicolumn{5}{|l|}{ FREQUENCY OF SOCIAL CONTACTS } \\
\hline Family/relatives & -0.16 & -0.05 & 0.05 & 0.01 \\
\hline Deaf club visits & 0.02 & -0.05 & 0.06 & 0.11 \\
\hline
\end{tabular}

Note: ${ }^{*}=p<0.05,{ }^{* *}=p<0.01$

${ }^{1}$ Measured by the Gothenburg Quality of Life instrument (GQL) (Tiblin et al., 1990), as reported in Werngren-Elgström et al. (2003b).

2 Measured by the Geriatric Depression Scale (GDS) (Sheijk \& Yesavage, 1986), as reported in Werngren-Elgström et al. (2003b). 